\title{
Insuficiente Escolaridade de Química Orgânica do Ensino Pré-Universitário Português
}

\section{SALDANHA*}

0 curriculum de algumas disciplinas do ciclo básico e pré-clínico do curso de medicina tais como Bioquímica, Biologia, Farmacologia e Microbiologia fundamenta-se maioritariamente no conhecimento de Química Orgânica (Q0), no que respeita a composição, estrutura e propriedades das funçōes químicas. Na Europa e nos Estados Unidos da América a aprendizagem das generalidades de $Q 0$ decorre na fase do ensino secundário, em proporção variável no conjunto das Quimicas Geral, Inorgânica e Orgânica.

Em Portugal, 6\% do ensino total de Química do $12^{\circ}$ ano é destinado à $Q 0$ [1]. Esta percentagem é manifestamente insuficiente, como foi demonstrado em estudos do domínio da Educação Médica, efectuados pelo Instituto de Bioquímica da Faculdade de Medicina de Lisboa (FML) [2-5].

Apesar de se estar na última década do século XX, e de se legislar sobre autonomia universitária, não se vislumbra nenhuma mudança nos requisitos dos conteúdos da Q0. A comprovar o que se disse, está a última Prova Específica de Química (11 de Junho, 1994): em 6 perguntas (com um total de 15 alíneas) apenas duas alíneas recaíram na área da Q0; perfazendo 7 pontos no total de 100 pontos.

Será oportuno (e indispensável) realçar que a prova "Específica" é apenas título sem correspondência prática; porque 0 conteúdo programático não foi definido pelas Faculdades de Medicina (FM) nem, que se saiba, por qualquer outro Estabelecimento do Ensino Superior a cujo dominio compete. Aqui reside a "cronicidade" da deficiência curricular pré-universitária apresentada pelos discentes admitidos, e que se traduz por exemplo, na dificuldade em compreender (i) a representação tridimensional das proteinas, (ii) a relação estrutura/função de biomoléculas, ou (iii) o funcionamento molecular do metabolismo celular. Os alunos têm conhecimentos insuficientes sobre as propriedades das ligações C-H e dos grupos funcionais, para além de outras, que em sentido figurativo corresponde a incapacidade de todos nós em correr sem primeiro termos aprendido a andar.

Para colmatar a carência curricular, têm sido adoptadas soluçöes de emergência, designadamente pela inserção do ensino/aprendizagem de Quimica Orgânica (i) no programa de Bioquímica (anos lectivos de 1978 a 1984), ou (ii) antecedendo (aulas de "reciclagem") o curriculum da disciplina de Bioquímica (anos lectivos de 1984 a 1992). Esta acção didática foi abandonada, nos anos lectivos subsequentes a 1992 por diversos motivos, em especial, (i) o ensino limitado a aulas intensivas de revisão (por carência de tempo) tiveram reduzida eficácia (2-5); (ii) o conteúdo programático da Q0 não era assimilado pelos alunos na escolaridade desponivel, e (iii) por consumir tempo destinado ao ensino da Bioquimica.

Na realidade, à Bioquímica não compete ensinar Q0, do mesmo modo que, por exemplo, ao programa da Matemática do ensino secundário não pertence leccionar a tabuada.

A partir de 1992 aconselhou-se a auto-aprendizagem de $Q 0$ aos alunos recém-admitidos, mediante indicação de palavras-chave consideradas imprescindiveis para 0 ensino da Bioquimica e de bibliografia pertinente.

Na prática, a aplicação daquelas estratégias metodológicas resultou que os discentes recorrem à memorização como meio auxiliar de conciliar o binómio aprendizagem/tempo. A utilização exclusiva da memória como método de aprendizagem apresenta, como consequências nefastas, 0 pseudo-saber e 0 esquecimento [6 e 7].

É necessário espaço e tempo para que qualquer novo conhecimento seja apreendido, raciocinado, moldado e integrado com o pré-existente, isto é, seja exercitado. A elaboração contínua do conhecimento torna o homem culto, com capacidades acrescidas de relacionar, associar, e aplicar a outras áreas do saber, predispondo-o a prática da interdisciplinaridade. 0 crescimento científico ocorre naturalmente em todos aqueles possuidores de niveis superiores de conhecimento, objectivo esse a atingir pelos licenciados. Como consequência 0 processo educativo alcançaria qualidade com reflexo natural num maior prestigio das Faculdades

Em conclusão, sugere-se como proposta de mudança que:

a) a adopção de programa e a inclusão de escolaridade adequada de $\mathrm{QO}$ ocorra no $12^{\circ}$ ano do ensino secundário e/ou num ano "vestibular", precedendo a admissão no Ensino Superior.

b) a fixação dos conteúdos em Química Orgânica, necessários ao ensino das disciplinas do ciclo básico do curso de Medicina seja feita pelas Faculdades de Medicina.

c) a definição dos requisitos e respectivos níveis, isto é, o enunciado dos objectivos científicos e humanisticos a demonstrar pelo candidato, seja competência das FM.

d) a aferição e a selecção dos candidatos fique à responsabilidade das FM, mediante metodologias adequadas

0 sistema em vigor será burocraticamente cómodo mas não deixa de ter um inconveniente fundamental: é pedagogicamente ineficaz, perante os requisitos estabelecidos pelas Faculdade de Medicina.

\section{BIBLIOGRAFIA}

1. C. Saldanha, Proposta de reestruturação das perguntas de quimica nas provas especificas de biologia, fisica e química e suas implicaçōes. Educação Médica 1 (1993) $18-26$.

2. J. Martins e Silva, Acesso à Faculdade de Medicina de Lisboa. A avaliação dos conhecimentos especificos de quimica e pertil sócio-cultural dos alunos admitidos nos anos lectivos de 1989/1990 e 1990/1991. BFMIL. 1991: II Série, $n^{\circ} 8$, p. 20

3. J. Martins e Silva, D. Santos, S. Marques, C. Moreira, Preparação real dos alunos candidatos ao curso de medicina, na área da quimica. J. Soc. Ciên. Med. CXLVII (1984) 28-32.

4. C. Saldanha, Y. Pinto, M. Nunes e J. Martins e Silva, Apreciação de uma avaliaçã̀o diagnóstica precedente ao ensino de bioquímica em 1986/1987. Actas do IV Cong. Nac. Educ. Med. FML ed. (1988) 61-76.

5. C. Saldanha, C. Moreira, Y. Pinto, M. Nunes e J. Martins e Silva, Avaliação diagnóstica dos interesses, vivências e conhecimentos da quimica dos alunos admitidos a FML em 1989/1990. Acta Med. Port. 4 (1991) 37-42.

6. E. Rico, J. Galindo, P. Marset, Remembering bioche. mistry: a study of the patterns of loss of biochemical knowledge in medical students. Biochem Educ. 9 (1881) 100.

7. M. Saffran, WB. Kennedy, PR. Jr Kelley, Use of nationa/ board examinations to estimate retention of biochemistry. Biochem Educ. 9 (1981) 97-99.

\section{AGRADECIMENTOS}

Agradece-se à Sra. D. Emilia Alves pela dactilografia do manuscrito.

* Instituto de Bioquímica da FML (Director: Prof. Doutor J. Martins e Silva) 


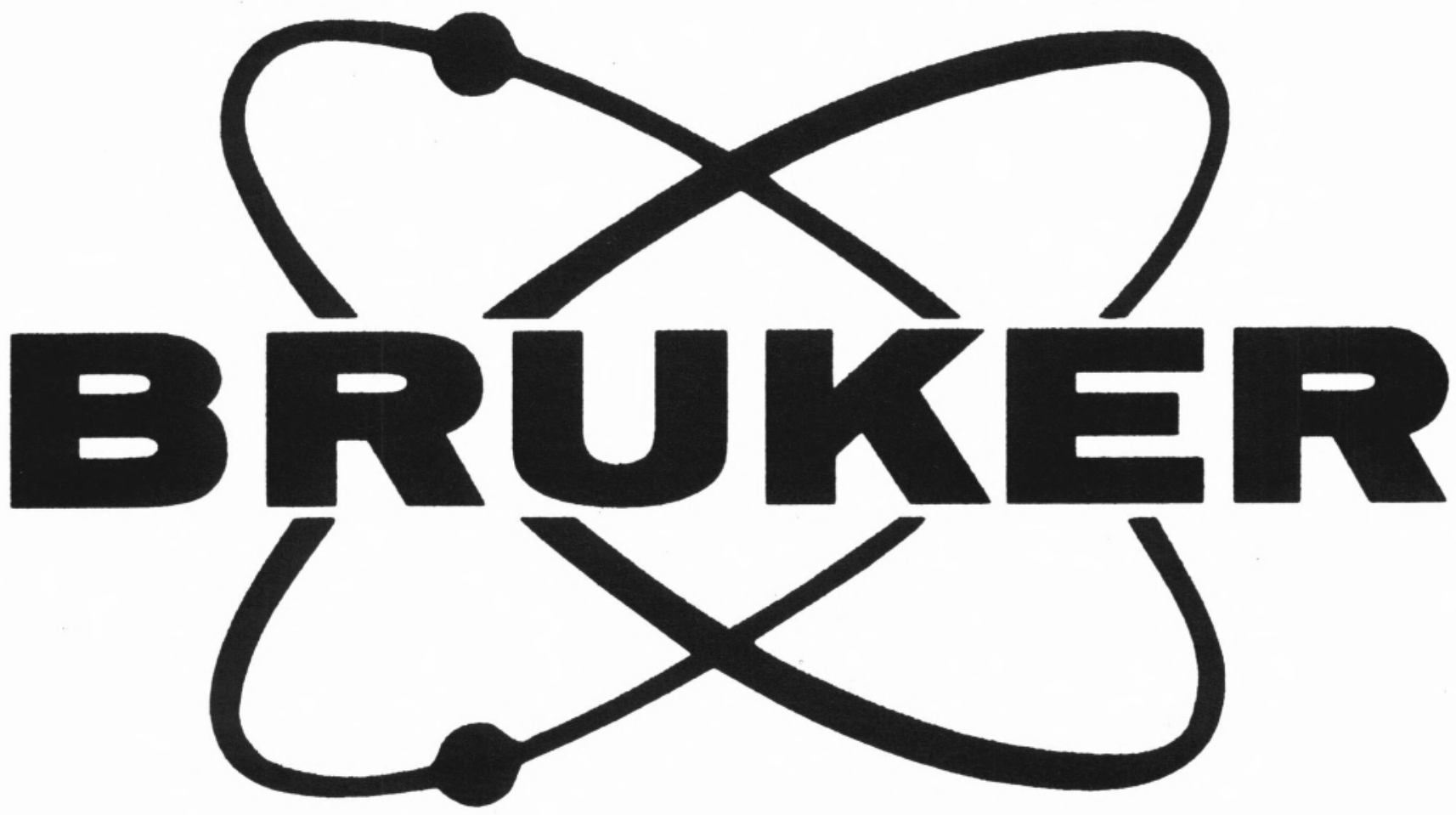

$\mathbf{N} \mathbf{M}: \mathbf{E P R}: \mathbf{F} \mathbf{T}-\mathbf{I} \mathbf{R}: \mathbf{M} \mathbf{S}$

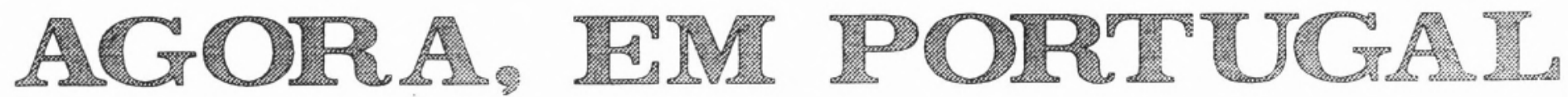

囱

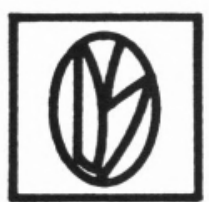

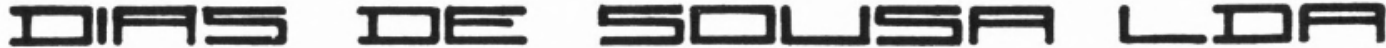

\section{INSTRUMENTAÇÃO ANALITICA E CIENTIFICA}

QUINTA DA PIEDADE, LOTE 15, R/C - 2625 PÓVOA DE STA. IRIA - TEL. (01) 9592316, 9592409 - FAX (01) 9590813 RUA GONÇALO CRISTOVÃO, 294, 7. ${ }^{\circ}$ ET - 4000 PORTO - TEL. (02) 310839, 2082490 - FAX (02) 323573

CANADA DOS FOLHADAIS, N. ${ }^{\circ} 15$ - 9700 ANGRA DO HEROISMO - AÇORES - TEL. (095) 32512 - FAX (095) 31338 